\title{
High Speed Thermal Imaging on Ballistic Impact of Triaxially Braided Composites
}

\author{
Joel P. Johnston, J. Michael Pereira, Charles R. Ruggeri, and Gary D. Roberts \\ NASA Glenn Research Center, 21000 Brookpark Road, Cleveland, OH 44135
}

\begin{abstract}
Ballistic impact experiments were performed on triaxially braided polymer matrix composites to study the heat generated in the material due to projectile velocity and penetration damage. Quantifying the heat generation phenomenon is crucial for attaining a better understanding of composite behavior and failure under impact loading. The knowledge gained can also be used to improve physics-based models which can numerically simulate impact of composites. Triaxially braided (0/+60/-60) composite panels were manufactured with T700S standard modulus carbon fiber and two epoxy resins. The PR520 (toughened) and 3502 (untoughened) resin systems were used to make different panels to study the effects of resin properties on temperature rise. Ballistic impact tests were conducted on these composite panels using a gas gun, and different projectile velocities were applied to study the effect on the temperature results. Temperature contours were obtained from the rear surface of the panel during the test through a high speed, infrared (IR) thermal imaging system. The contours show that high temperatures were locally generated and more pronounced along the axial tows for the T700S/PR520 composite specimens; whereas, tests performed on T700S/3502 composite panels using similar impact velocities demonstrated a widespread area of lower temperature rises. Nondestructive, ultrasonic C-scan analyses were performed to observe and verify the failure patterns in the impacted panels. Overall, the impact experimentation showed temperatures exceeding $525 \mathrm{~K}\left(485^{\circ} \mathrm{F}\right)$ in both composites which is well above the respective glass transition temperatures for the polymer constituents. This expresses the need for further high strain rate testing and measurement of the temperature and deformation fields to fully understand the complex behavior and failure of the material in order to improve the confidence in designing aerospace components with these materials.
\end{abstract}

\section{INTRODUCTION}

The application of composite materials for aerospace structures provides many benefits including weight savings. Specifically, triaxially braided composites are being utilized in jet engine fan containment systems due to the delamination resistant behavior of the material [1]. This trait is particularly useful for fan containment systems as these structures are designed to sustain and contain a turbofan blade 
impact in the case of a blade-out event. Additionally, the containment system has to maintain structural integrity under dynamic loadings caused by the imbalance of the fan rotor after the blade-out event. A significant amount of high velocity impact testing has been performed for carbon fiber reinforced polymer matrix composites with triaxial braids [1-8] and other textile architectures [9-16] in order to determine the impact resistance of the material. Several studies have used infrared (IR) thermal imaging systems on woven and unidirectional composite specimens to monitor the behavior and energy absorption during low velocity Charpy impact experiments or drop tests [17-25]. These sources noted temperature increases up to $308 \mathrm{~K}\left(95^{\circ} \mathrm{F}\right)$ for relatively low energy impact experiments. Work has also been performed, using gas gun equipment and rifles, on high speed impact of woven composite panels and has shown that temperatures above $475 \mathrm{~K}\left(395^{\circ} \mathrm{F}\right)$ were generated during impact [26,27]. The high temperatures from these impact studies approach the glass transition temperature of the polymer constituent. Therefore, it is necessary to conduct further studies on damage resistant material, such as triaxially braided composites, as well as determine the effects that different polymer constituents have on the temperature response.

The present study utilized gas gun equipment and a high speed thermal imaging system to quantify the temperature response during impact of triaxially braided composite panels. The panels were manufactured with carbon fiber, and two types of polymer constituents were used to make toughened and untoughened composites. The triggering of the thermal imaging system enabled the capture of the complete temperature-time response of the event, including before, at, and after the projectile impact on the triaxially braided panel. Due to the various obstacles and reflections in the radiation path, a detailed temperature measurement process was applied to transform the radiometric, measured temperature into actual temperature. The temperature contours for both types of composite materials were compared with failed regions determined through Ultrasonic C-scan analyses of the impacted panels.

\section{IR BACKGROUND THEORY}

A detailed calibration and correction process was used for the IR camera system in order to account for losses and reflections in the radiation path and transform the radiometric, measured temperature into the actual temperature of the panel surface. Since IR cameras measure the radiance, $L$, of a surface, the process is based on fundamental radiometric physics and is achieved by balancing the energy observed from the surface. The full details of the fundamental radiation physics and formulations are provided in comprehensive references such as Vollmer and Möllmann [28]. The radiation laws are based on the assumption that the object is a blackbody, which is an idealized object that absorbs radiation regardless of wavelength or direction and emits radiation at every wavelength independent of direction. The plots in Figure 1(a), generated using the aforementioned radiation laws, show examples of spectral radiance as a function of wavelength and the effect that temperature has on the radiance emitted from a blackbody. The integration of the spectral radiance plot produces the necessary radiance terms needed for the energy balance. However, as illustrated in Figure 1(b), IR sensors do not have the ability to detect the entire radiation spectrum and the integration of a spectral radiance plot 
with a limited wavelength band requires a complex solution methodology [29] since an analytical solution does not exist for arbitrary values of lower and upper limits. Additionally, most objects, including composites, do not exhibit idealized blackbody characteristics and behave more like so-called graybodies, which have lower emissivities causing the object surface to emit less radiation than that of blackbodies (Figure 1b).

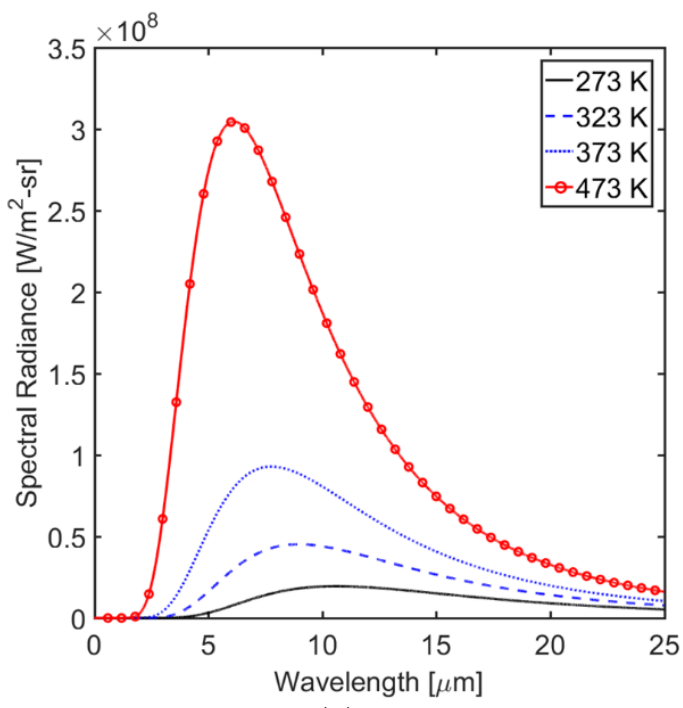

(a)

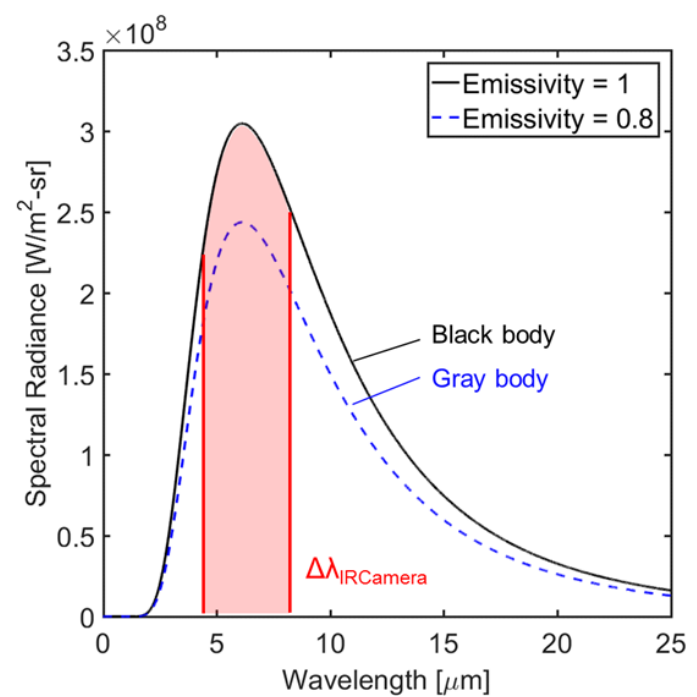

(b)

Figure 1. Spectral radiance plots of a blackbody for various (a) absolute temperatures and (b) emissivities

The derivation of the band radiance (depicted by the red highlighted region in Figure 1b) is necessary to solve for the total radiation path from the object to the IR detector. A schematic of the radiation path for an impact experiment is shown in Figure 2 and the balance of the radiant power terms that are incident on the IR detector, $\Phi_{\text {det }}$, is given in Equation 1.

$$
\Phi_{\text {det }}=\varepsilon_{o b j} \tau_{w i n} \Phi_{o b j}+\left(1-\varepsilon_{o b j}\right) \tau_{w i n} \Phi_{r e f l 1}+\left(1-\tau_{w i n}\right) \Phi_{r e f l 2}
$$

The radiant power from the surface of the object, $\Phi_{o b j}$, is multiplied by the object's emissivity, $\varepsilon_{o b j}$, to determine the emitted radiant power from the surface. Additionally, the reflectivity properties of the object and the unwanted radiation from the surroundings send an ambient reflection, $\Phi_{\text {refll }}$, from the surface of the object to the sensor. An IR window, installed in the impact chamber wall, allows the IR camera to view inside the chamber to focus on the composite panel, but the transmission losses due to the transmissivity of the window, $\tau_{\text {win }}$, reduces the magnitude of radiant power being sent from the object. The IR window also introduces another reflection power term, $\Phi_{\text {refl2 }}$, in the energy balance. The radiant power terms are converted to radiance terms for direct insertion of the radiance values measured from the IR camera, and the equation is rearranged into the form shown in 
Equation 2 in order to calculate the radiance of the object and solve for the temperature.

$$
L_{o b j}\left(T_{o b j}\right)=\frac{1}{\varepsilon_{o b j} \tau_{w i n}}\left[L_{\text {det }}-\left(1-\varepsilon_{o b j}\right) \tau_{w i n} L_{r e f l 1}-\left(1-\tau_{w i n}\right) L_{r e f l 2}\right]
$$

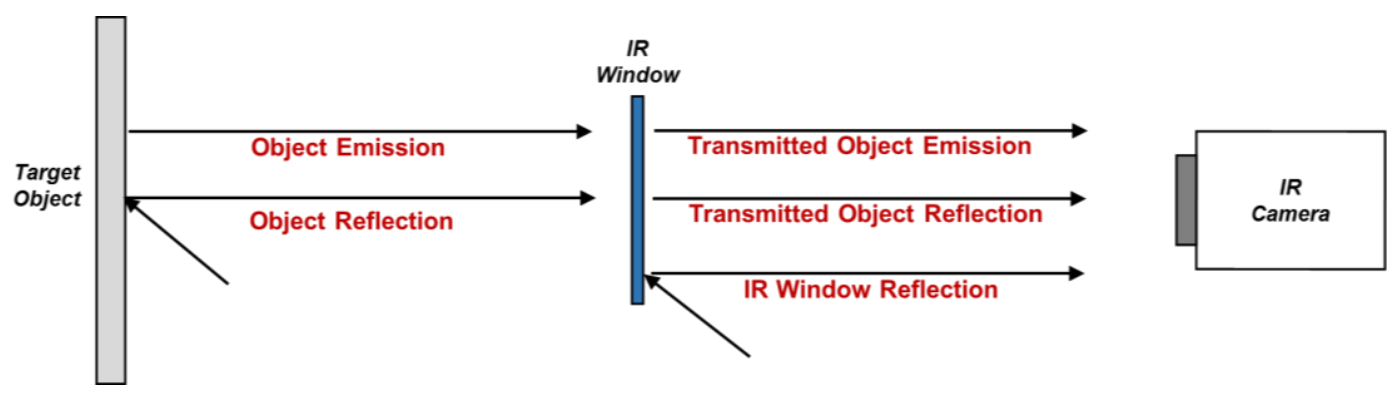

Figure 2. Schematic of radiation path for an impact equipment setup

\section{EQUIPMENT AND METHODS}

The material in this study was a six layer laminate of triaxially braided composite consisting of Toray ${ }^{\circledR}$ T700S standard modulus carbon fiber and two epoxy resins with a total thickness of $3.18 \mathrm{~mm}$ (0.125 inches). The Cycom ${ }^{\circledR}$ PR520 (toughened) and Hexcel® 3502 (untoughened) resin systems were used to make different panels to study the effects of resin properties on temperature rise. The fiber preforms consisted of a quasi-isotropic 0/+60/-60 braid with $24 \mathrm{~K}$ tows in the axial direction and $12 \mathrm{~K}$ tows in the bias directions, and the composite panels were manufactured using a resin transfer molding process. The average fiber volume fraction value determined for the composite panels was approximately $56 \%$. The composite panels were $61 \mathrm{~cm}$ (24 in.) square plates from which four smaller $30.5 \mathrm{~cm}$ (12 in.) square panels were cut for the impact tests.

The ballistic impact response was measured by impacting the composite panels with projectiles at a normal incidence using a single stage gas gun with a $5.1 \mathrm{~cm}(2$ in.) bore and a length of $3.66 \mathrm{~m}$ (12 ft.) as per ASTM D8101 [30]. The composite test specimens were clamped in a circular fixture with an aperture of $25.4 \mathrm{~cm}$ (10 in.). Slipping was prevented at the boundary by applying 28 bolts which fixed the front clamp of the fixture, the specimen, and the rear fixture plate. The projectile was a thin walled hollow Al 2024 cylinder with a nominal mass of $50 \mathrm{gm}$. and a front face with a compound radius. The projectile was used to impact the front surface of the composite panel. Further details of the impact setup and the projectile design are given by Pereira et al. [5,7]. A Telops FAST-IR 2K camera was used to capture the temperature fields on the composite panel and was positioned to view the back surface of the panel through an Argon coated IR window. The Telops IR camera is operational in the 3-5.4 $\mu \mathrm{m}$ wavelength range and is capable of performing image windowing to achieve frame rates up to 90,000 frames per second. For the present impact tests, the IR camera was set to capture a $256 \times 56$ pixel area at 10,000 frames per second. 
The temperature correction process, previously described in the background theory section, was applied to the IR camera measurements using the expression in Equation 2. The calibration procedures outlined in the ASTM E1862 standard [31] were followed to determine the ambient reflections and involved placing an IR reflector parallel to the target object or the IR window. Blackout curtains were fixed to the inside walls of the gas gun receiving chamber to minimize the ambient reflections as much as possible. Similarly, the emissivity of the composite panel was calculated using the calibration methods in the ASTM E1933 standard [32]. The contact thermometer approach was adopted from this standard where the composite panel was heated to various temperatures, and the thermocouple measurements were compared to those from the IR camera. The average emissivity values measured for the T700S/PR520 and T700S/3502 composite materials were $85.9 \%$ and $77.1 \%$, respectively. The manufacturer data for the IR window specified that the average transmissivity was $96 \%$ for the operable wavelength range of the IR camera. The validity of the temperature correction process was assessed by heating the different composite systems and applying the algorithm to the radiometric IR data. Figure 3 shows the results from this assessment where "IR" represents the radiometric IR data and "Corrected IR" denotes the IR temperature measurement with the applied correction algorithm. These plots demonstrate that the data processed with the correction method provides better correlation with the thermocouple data. It is also important to note that the error between the thermocouple and radiometric IR data becomes larger for higher temperatures. Consequently, the extrapolation of the curves indicates as much as a $30 \mathrm{~K}$ difference for a thermocouple temperature of 525 $\mathrm{K}\left(485^{\circ} \mathrm{F}\right)$ which establishes the necessity of applying the correction method.

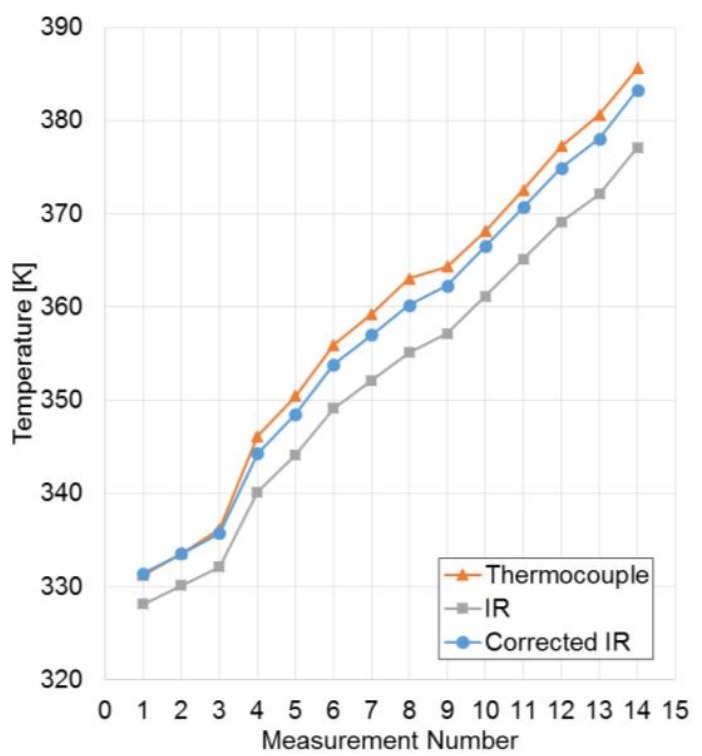

(a) $\mathrm{T} 700 \mathrm{~S} / \mathrm{PR} 520$

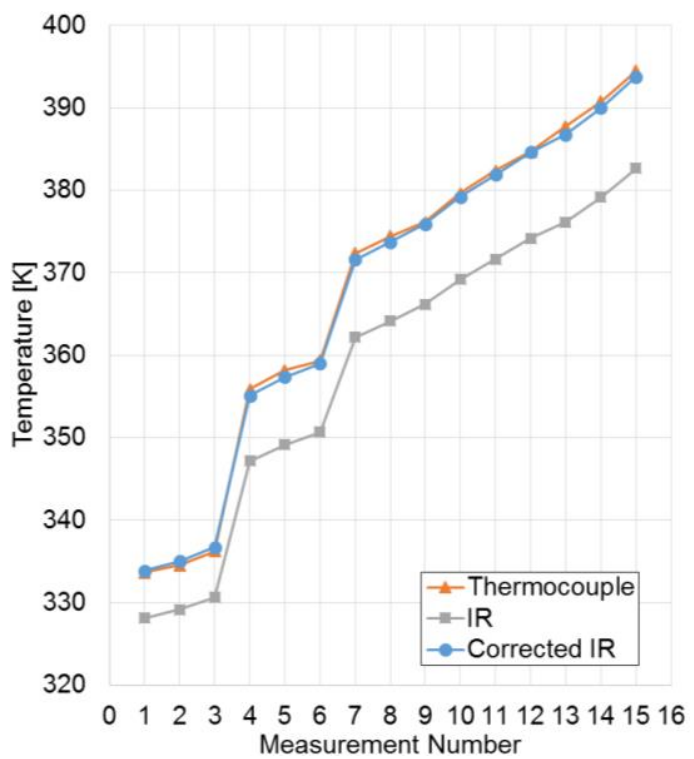

(b) $\mathrm{T} 700 \mathrm{~S} / 3502$

Figure 3. Verification trials of the temperature correction process for both types of composite systems 


\section{EXPERIMENTAL RESULTS}

Post-test images for the back side of the impacted T700S/PR520 and T700S/3502 composite panels are presented in Figure 4 for different projectile velocities. The images highlight several failure features visible in the central region of the panels and demonstrate the progressive development of failure. For the lower velocity impacts of the T700S/PR520 composite panels (Figure 4a), tow splitting and pullout occurred primarily along the axial direction. Figure 4(b) demonstrates the damage accumulation for a T700S/PR520 composite test which resulted in penetration. Comparatively, for similar lower velocity tests, the T700S/3502 composite panels (Figure 4c) did not exhibit the same severity of fiber damage near the impact site as the T700S/PR520 composite panels. However, there was a larger area of matrix damage surrounding the impact site for the more brittle T700S/3502 composite. The image of the penetrated T700S/3502 panel in Figure 4(d) shows a splintering failure pattern of the fibers opposed to the punch-out failure of material at the impact site shown for the penetrated T700S/PR520 composite tests.

In addition to the visible post-test failure modes, the difference in ductility between the two composites affected the temperature response during the impact event. Radiometric temperature contours for the T700S/PR520 and T700S/3502 composite tests are presented in Figure 5 and Figure 6, respectively, and display the IR features evident at impact for various projectile velocities. Significant temperature increases were generated during the impact event where local temperatures reached up to $525 \mathrm{~K}\left(485^{\circ} \mathrm{F}\right)$ for tests at the penetration threshold. The contours for the T700S/PR520 composite tests show localized temperature rises in the center of the frame with small rises in the resin surrounding the center bias fiber tows and more prominent rises in vertical resin areas around the axial tow. Similar temperature rises occurred during impact of the T700S/3502 composite panels, but the results differed from the T700S/PR520 composite tests in that the temperature rises were more prevalent in resin areas around the bias fiber tows and were not as distinct in the resin areas along the axial fiber tow. It is important to note that these high local temperatures exceed the resin glass transition temperature listed in the manufacturer datasheets, which is approximately $434 \mathrm{~K}\left(322^{\circ} \mathrm{F}\right)$ for the PR520 resin and $464 \mathrm{~K}\left(376^{\circ} \mathrm{F}\right)$ for the 3502 resin. Since the PR520 resin has a higher ductility, large, localized deformations developed during the tests which caused the generation of higher temperatures in the T700S/PR520 composite. Specifically, this local deformation allowed the projectile energy to be focused at the impact site. In contrast, the brittle behavior of the T700S/3502 composite enabled temperature rises in a large, widespread area of the panel. The variations in the temperature magnitudes and patterns between the composites suggests that the differences in material properties and local failure modes affected the mechanisms which generated heat within the material. 


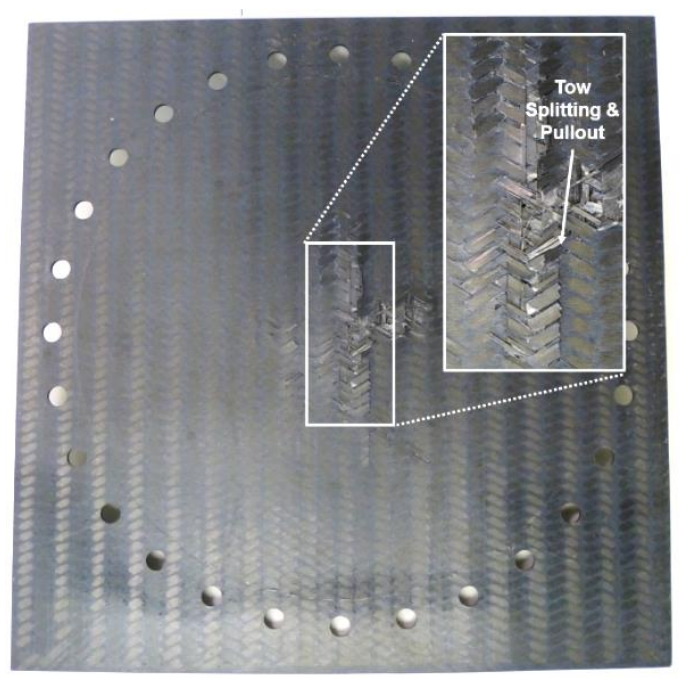

(a) $160 \mathrm{~m} / \mathrm{s}$

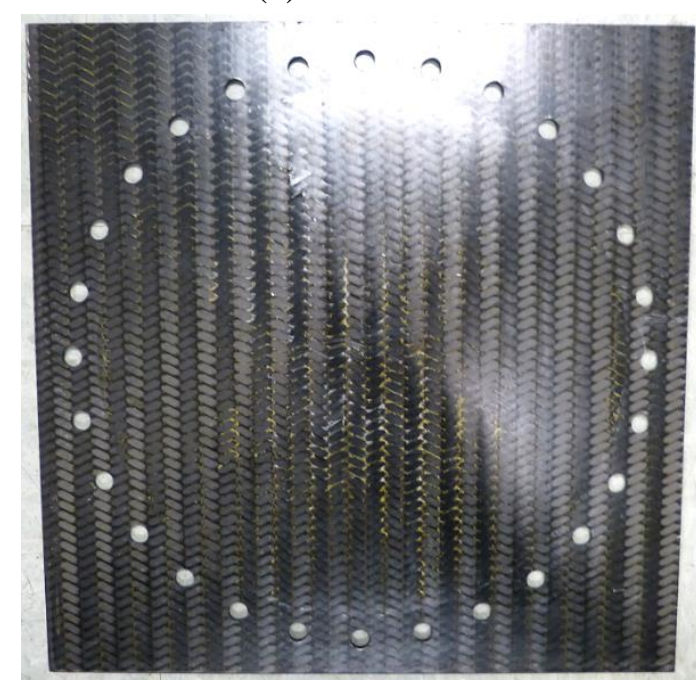

(c) $159 \mathrm{~m} / \mathrm{s}$

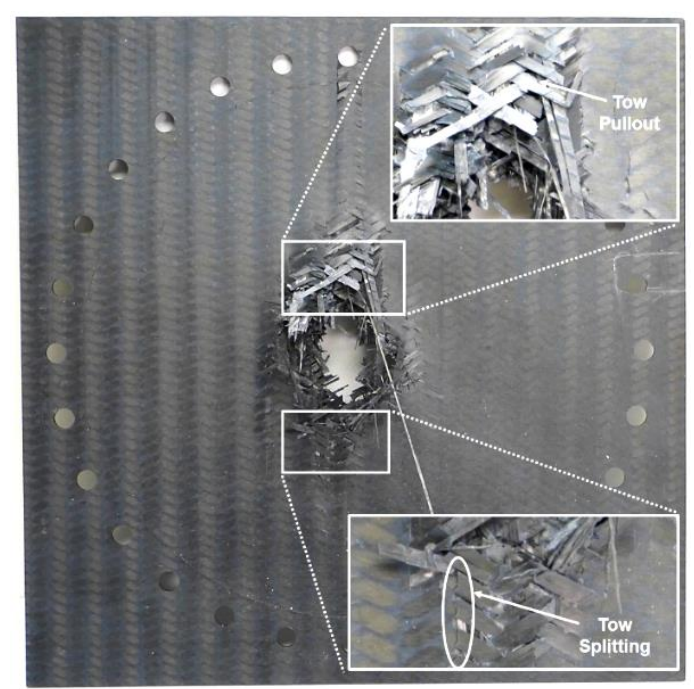

(b) $166 \mathrm{~m} / \mathrm{s}$ (Penetrated)

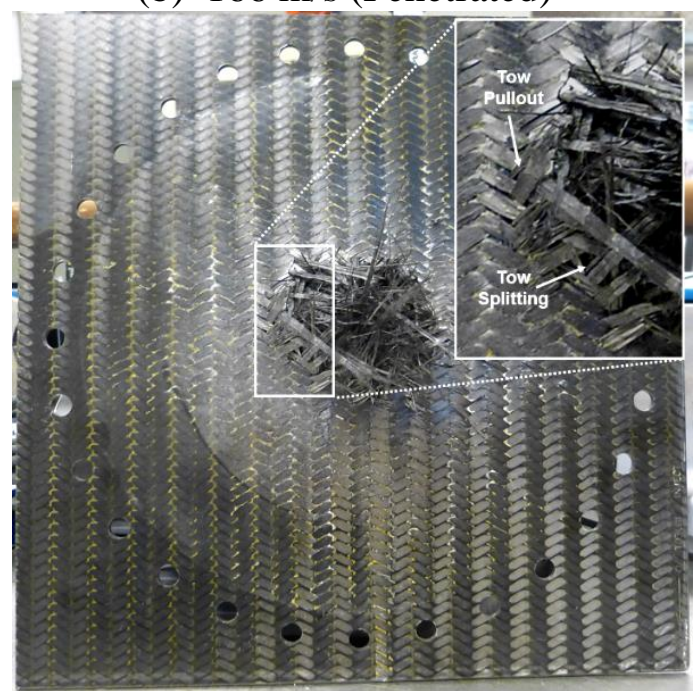

(d) $211 \mathrm{~m} / \mathrm{s}$ (Penetrated)

Figure 4. Images showing the back side of the failed (a,b) T700S/PR520 and (c,d) T700S/3502 composite panels impacted at different velocities

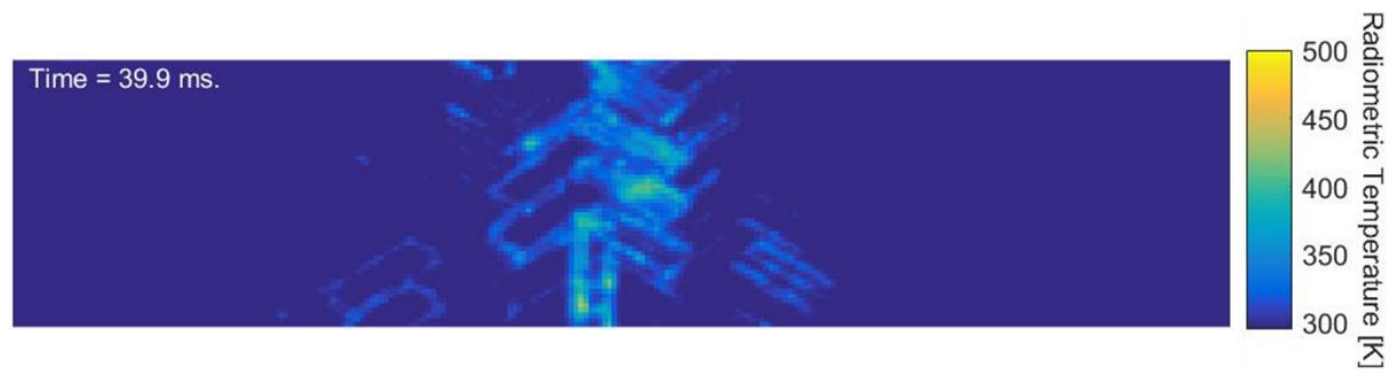

(a) Impacted at $160 \mathrm{~m} / \mathrm{s}$ 


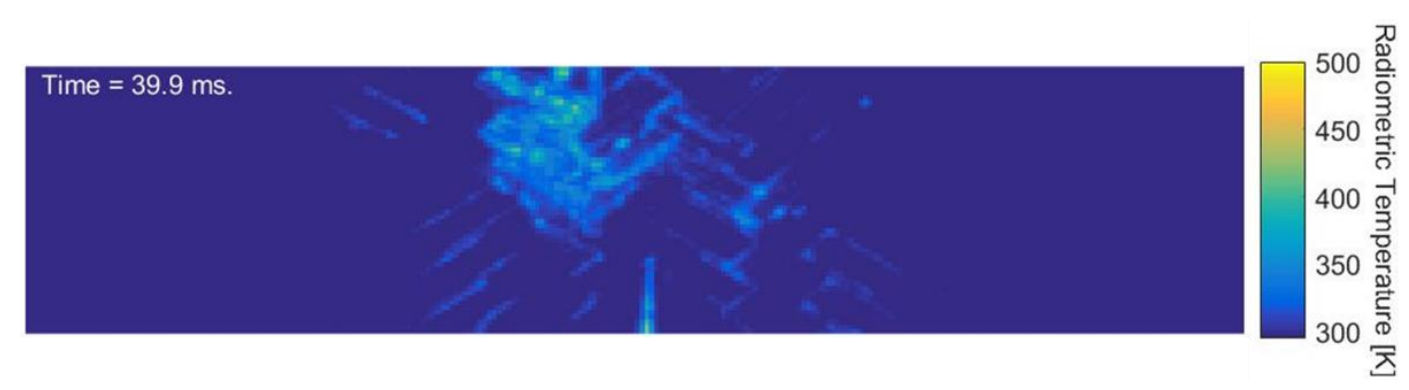

(b) Impacted and penetrated at $166 \mathrm{~m} / \mathrm{s}$

Figure 5. IR contours at impact for T700S/PR520 composite tests with different projectile velocities

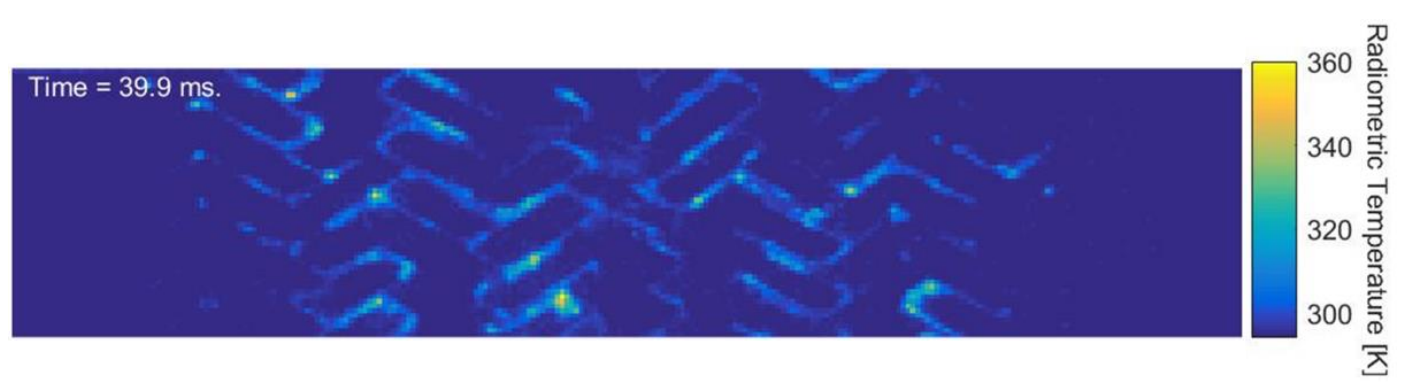

(a) Impacted at $159 \mathrm{~m} / \mathrm{s}$

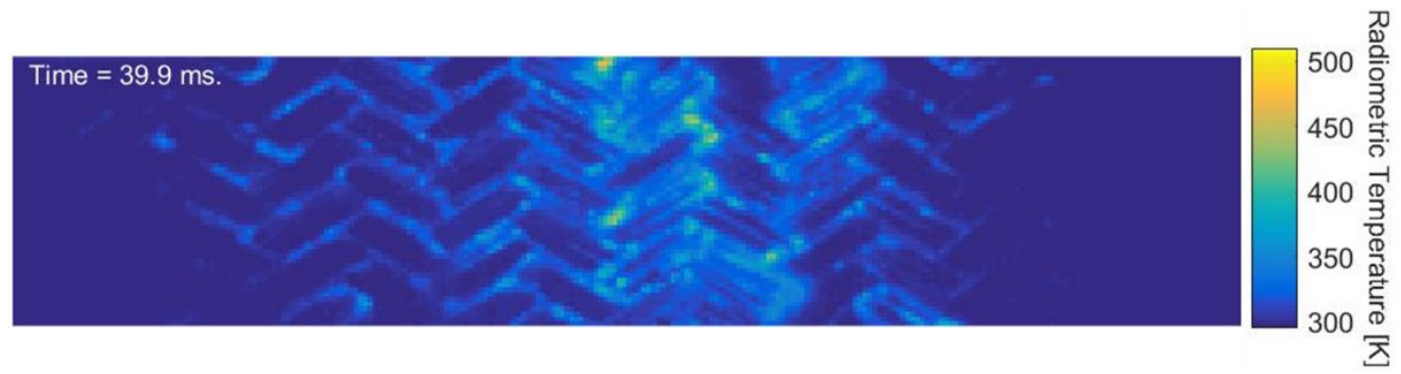

(b) Impacted and penetrated at $211 \mathrm{~m} / \mathrm{s}$

Figure 6. IR contours at impact for T700S/3502 composite tests with different projectile velocities

Maximum temperature values were extracted from the IR contours for each time increment of the impact tests to obtain the temperature-time responses shown in Figure 7 and Figure 8. The data was processed for each test to show impact occurring at $39.9 \mathrm{~ms}$. and IR camera frames were captured during the $0-39.8 \mathrm{~ms}$. time range to obtain a consistent temperature measurement of the composite surface before impact. The response shows a large temperature increase at impact and a cooling in temperature after impact. The penetrated impact test results show a sharp, smaller decrease in temperature which followed soon after impact due to the projectile penetrating the panel and moving into the IR camera's field of view for a short duration. The temperatures at impact and immediately after impact are emphasized in the narrower time range plots of the T700S/PR520 and T700S/3502 results shown in Figure 7(b) and Figure 8(b), respectively. The T700S/PR520 panels experienced a longer cooling period compared to that of the T700S/3502 results because the local, central failure of the T700S/PR520 panels created a debris cloud of failed material. 
The debris cloud affected the heat transfer mechanisms within the material and temporarily obstructed the line of sight between the IR camera and the remaining portion of the panel which caused inaccurate temperature measurements of the panel during this short time period. The widespread failure at impact for the T700S/3502 composite panels caused a smaller debris cloud in the central region and the debris cloud lasted a shorter amount of time. Therefore, the obstruction of the line of sight between the panel and the IR camera was reduced resulting in better accuracy of the temperature measurements and a shorter cooling period.

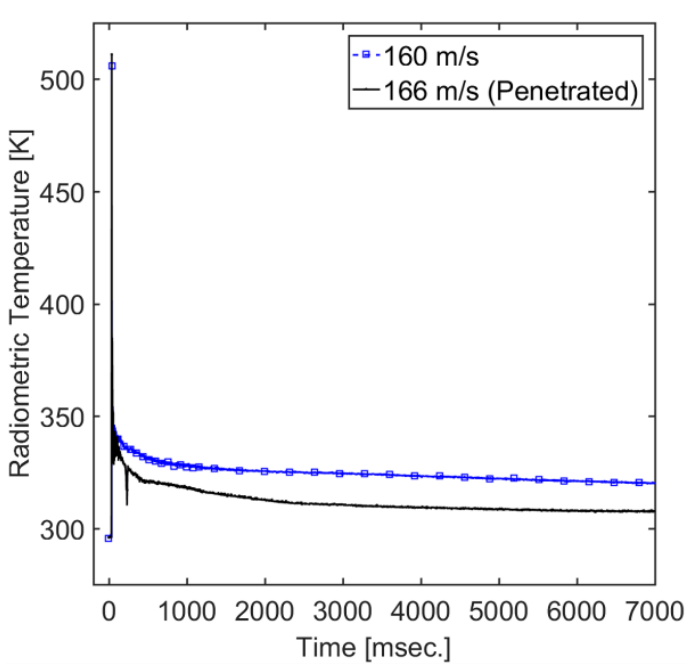

(a)

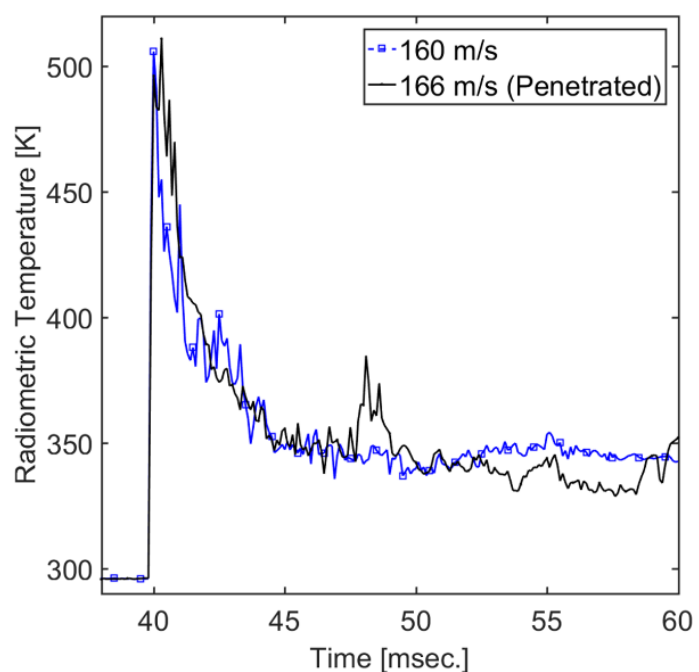

(b)

Figure 7. Temperature-time plot of (a) the entire time range for two T700S/PR520 composite tests and (b) a smaller time range focusing on the behavior at impact

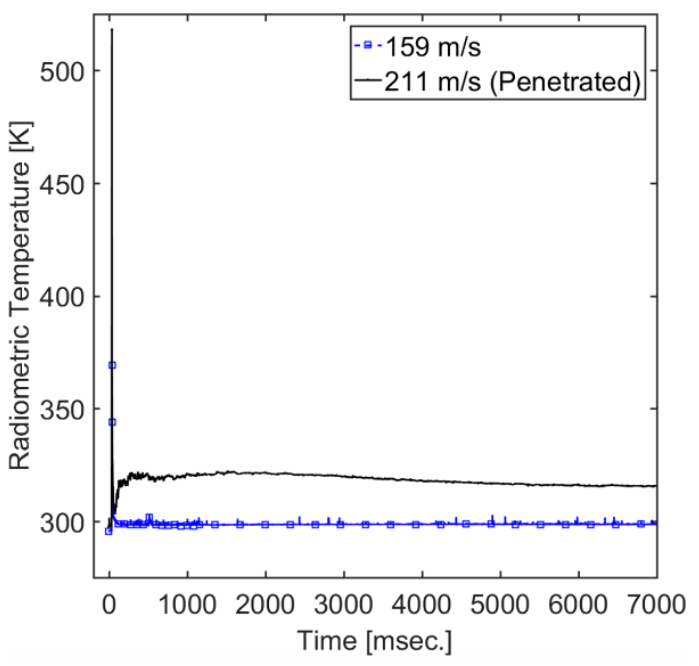

(a)

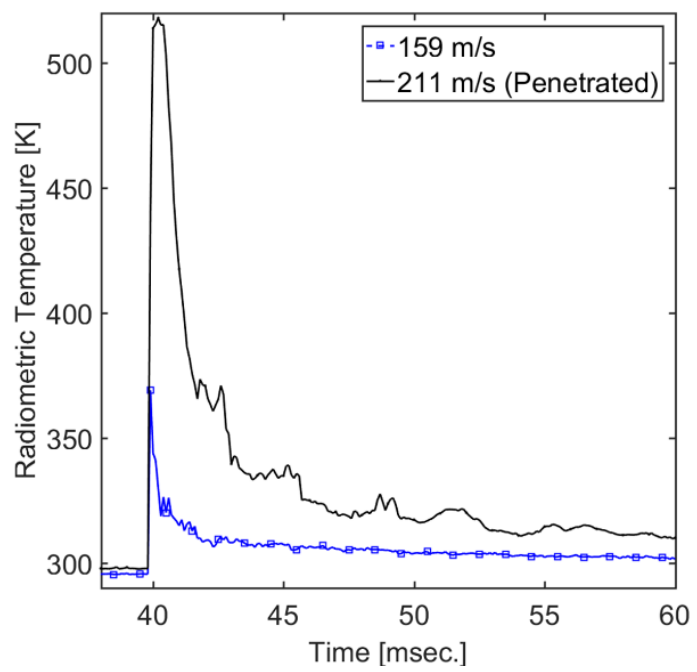

(b)

Figure 8. Temperature-time plot of (a) the entire time range for two T700S/3502 composite tests and (b) a smaller time range focusing on the behavior at impact 
The maximum temperature value generated at impact was calculated for each temperature-time response and plotted as a function of velocity (Figure 9). The plotted temperature values were corrected, using the process and expressions described in the IR background theory section, in order to perform a direct and accurate comparison. The plot shows that, for a specific projectile velocity, the T700S/PR520 composite tests produced higher temperatures compared to the T700S/3502 tests, but the material had a lower penetration threshold. As previously stated the higher temperatures generated in the T700S/PR520 composite was due to the higher ductility of the resin. The high temperatures occurred because the ductile, toughened resin deformed but maintained a bond with the fiber tows, and local failure initiated when a fiber tow fractured at its maximum strain. Furthermore, the concentration of the energy at the impact site enabled large local strains and failure in the T700S/PR520 composite causing lower penetration velocities. In contrast, local deformation and failure of polymer regions released the constraint on the fiber tows in the T700S/3502 composite tests resulting in a more widespread dispersion of the impact energy and higher penetration velocities. The differences in energy absorption behavior are further verified by the failure of the penetration tests shown in Figure 4 where the T700S/PR520 composite has a smaller punched out failure pattern and the T700S/3502 composite exhibits a splintering failure in a larger region of the panel.

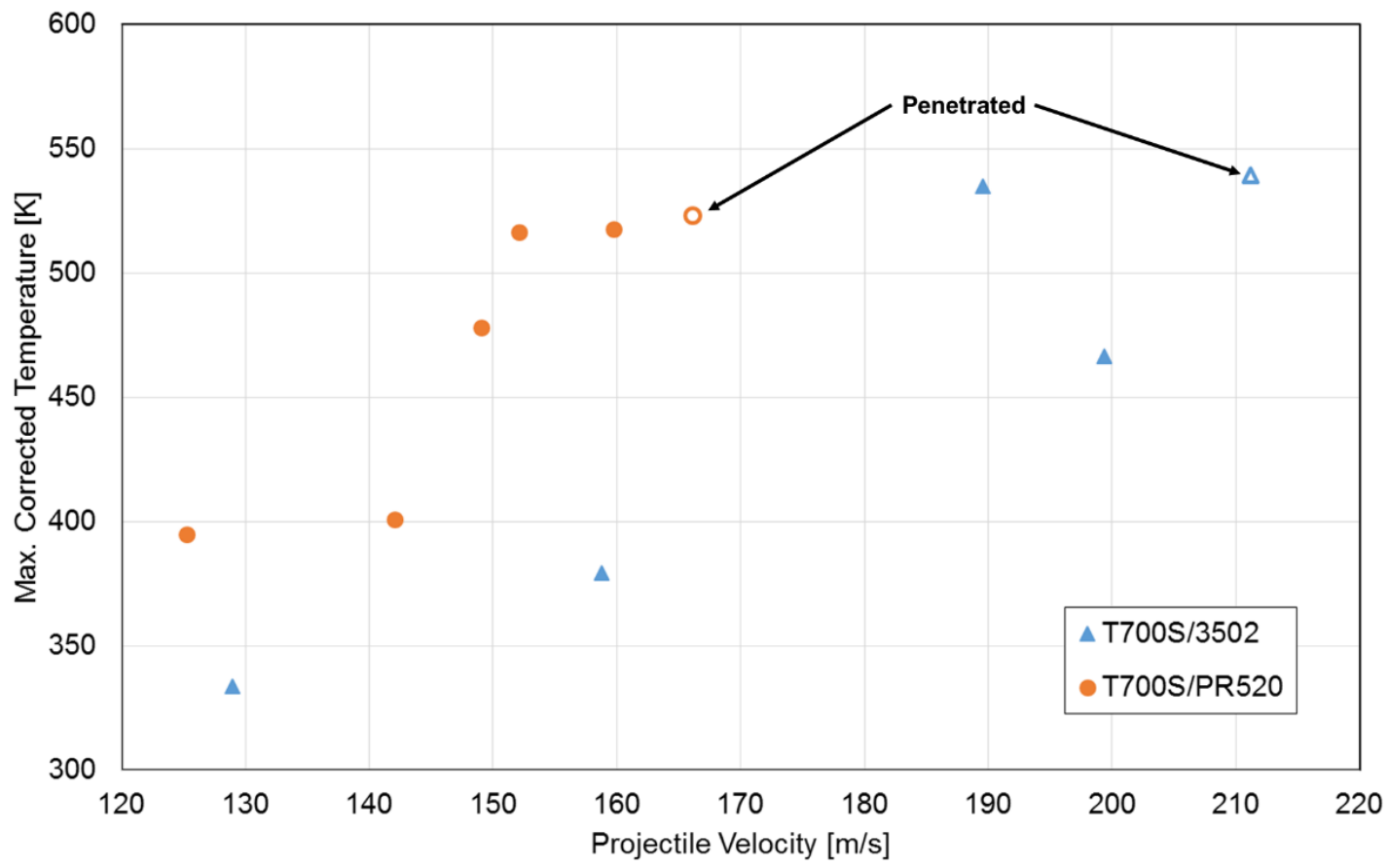

Figure 9. Maximum corrected temperature rises for composite tests at various impact velocities 


\section{NONDESTRUCTIVE ANALYSIS OF DAMAGE}

Nondestructive evaluation was performed using ultrasonic C-scan equipment on the composite panels before and after the tests to analyze the damage caused by impact. The C-scan results for the composite panels, both before and after the tests conducted at lower projectile velocities, are displayed in Figure 10 where the "AMP" in the legend represents the percentage of the transmitter transducer's signal amplitude that was able to permeate through the material to the receiver transducer. The maximum throughput of the signal amplitude was normalized using known, undamaged regions of the material in order to emphasize the damage. As a result, the maximum amplitude value is displayed for the bolt holes since they are through holes. The results show that the damage induced in the T700S/3502 panels was significantly more severe than the visible damage determined from the corresponding failure image presented in Figure 4(c). This provides further verification for the cause of the large spread of temperature rises previously shown in the IR contours for the T700S/3502 panel tests. Similar results are noticeable in the C-scan results for the T700S/PR520 composite panels (Figure 10d) where barely visible damage is detected but not as prevalent as the T700S/3502 composite results. Area fraction measurements of the damage shown in the post-test C-scan images were computed by creating a binary image and measuring the area of the region associated with damage. The area of the damaged region was divided by the total reference area, which was designated as the circular region defined by the centers of the bolt holes, and the area fraction values for each test are depicted in Figure 11 as a function of velocity. Overall, the C-scan analyses established that, for a particular velocity, there was approximately three times as much damage induced in the T700S/3502 composite compared to the T700S/PR520 composite.

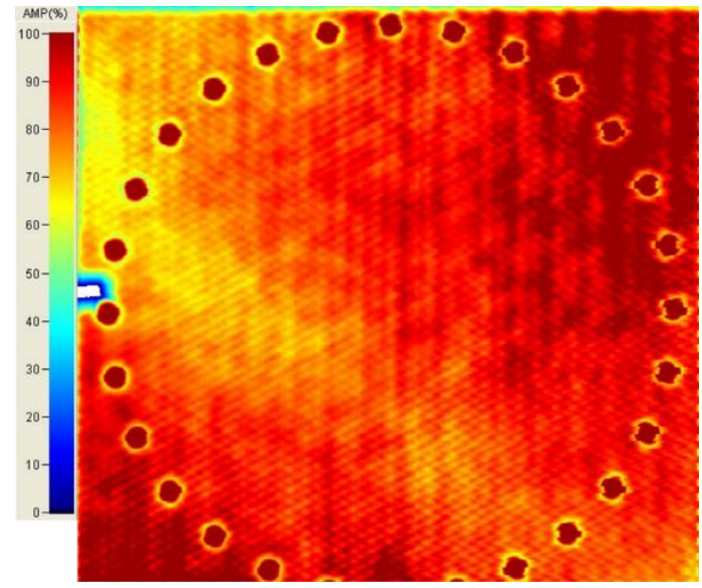

(a) $159 \mathrm{~m} / \mathrm{s}-$ Pretest

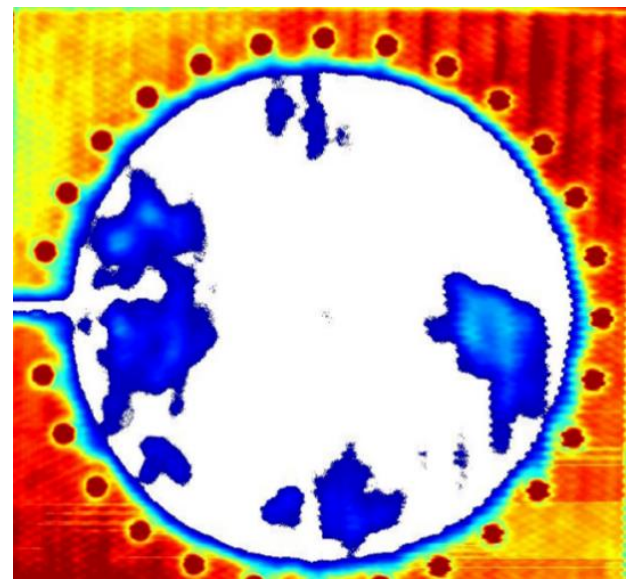

(b) $159 \mathrm{~m} / \mathrm{s}$ - Post test 


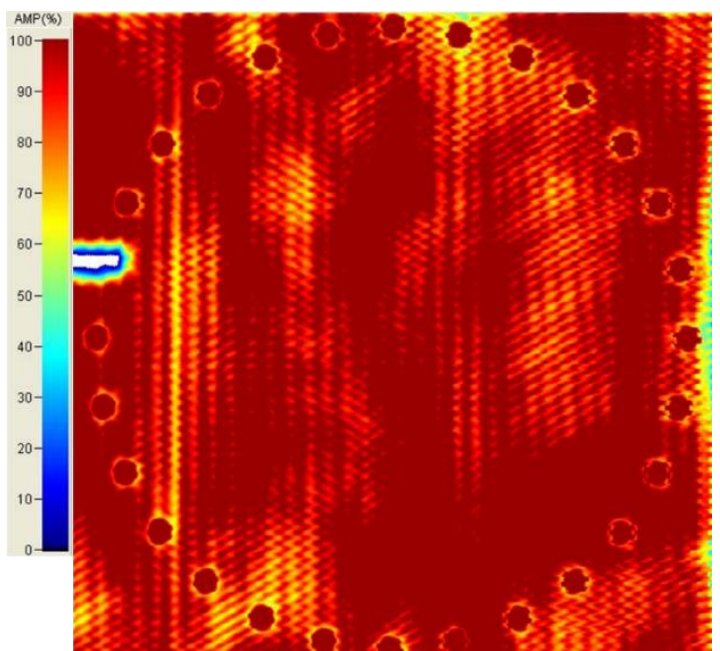

(c) $160 \mathrm{~m} / \mathrm{s}$ - Pretest

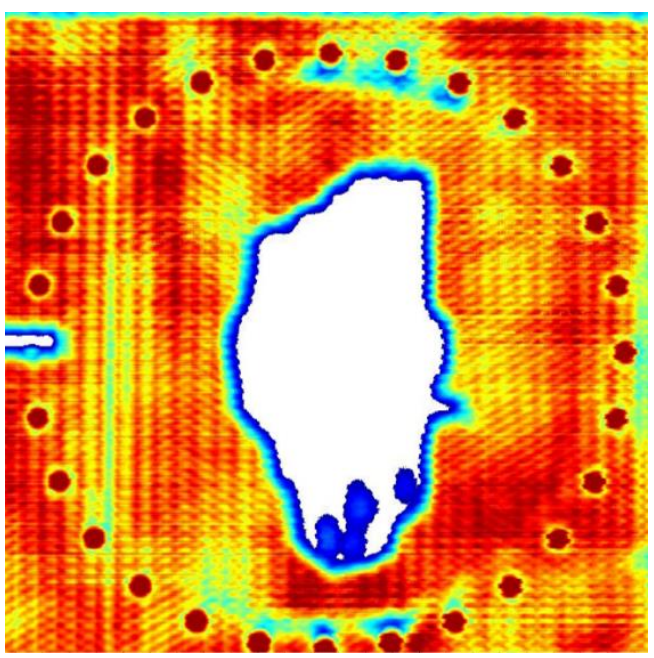

(d) $160 \mathrm{~m} / \mathrm{s}-$ Post test

Figure 10. C-scan images of (a,b) T700S/3502 and (c,d) T700S/PR520

composite panels

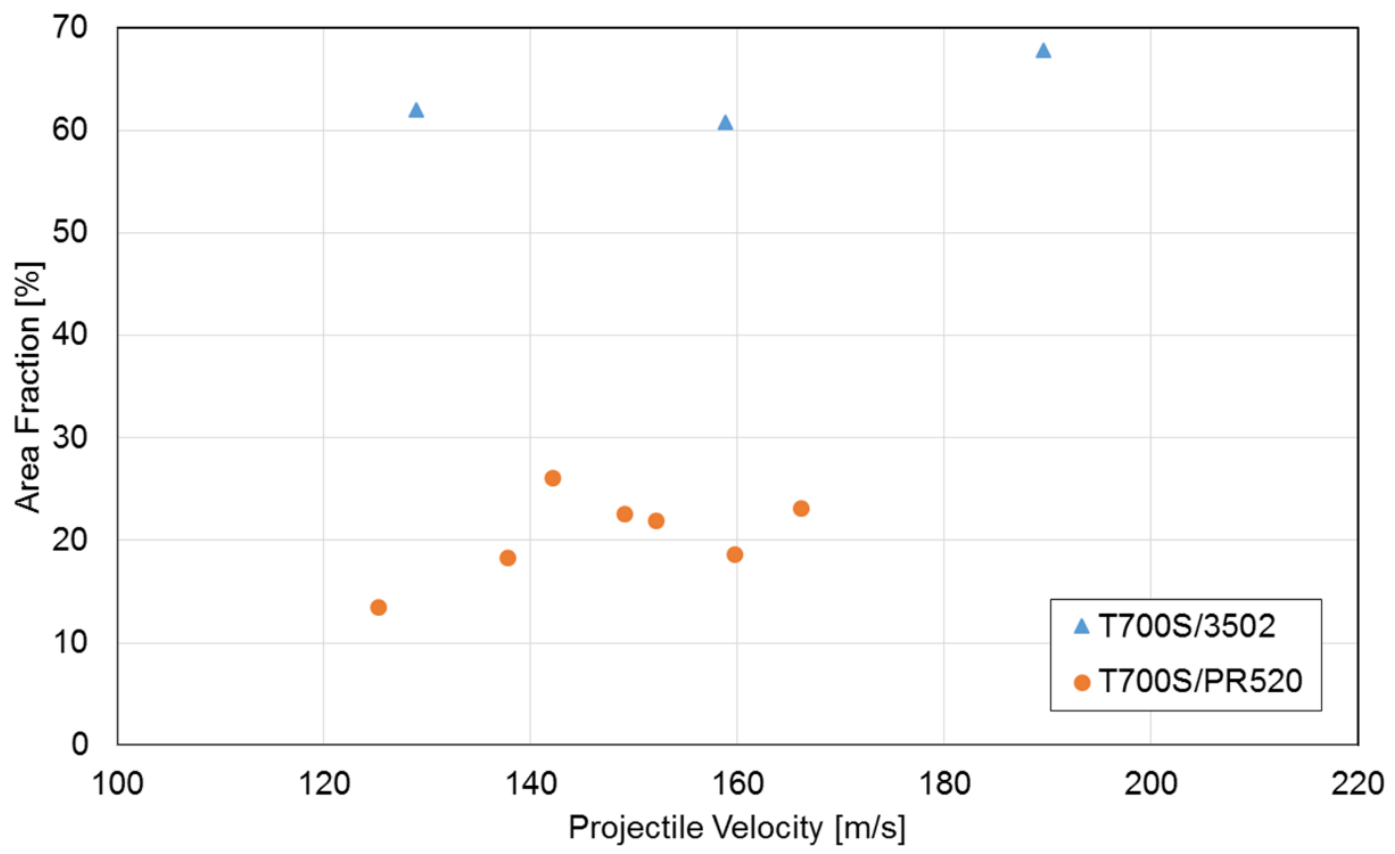

Figure 11. Area fractions measured from the damaged regions in the $\mathrm{C}$-scan images

\section{CONCLUDING REMARKS}

The current study used a single stage gas gun and a high speed, IR thermal imaging camera to examine the temperatures generated in composite materials during ballistic impact. Several panels were manufactured from T700S/3502 and T700S/PR520 triaxially braided composite material for impact experimentation. A temperature correction process was applied to radiometric IR camera values in order to obtain the actual temperature of the specimen at impact. This correction process 
was essential since the controlled heating trials indicated as much as a $30 \mathrm{~K}$ difference between the thermocouple and radiometric IR temperature measurements. The corrected temperatures generated by impact reached values over $525 \mathrm{~K}\left(485^{\circ} \mathrm{F}\right)$ which is well above the glass transition temperature of these materials. The temperature contours correlated with damage areas measured by $\mathrm{C}$-scan equipment. For a particular projectile velocity, higher and more localized temperature rises occurred in the toughened T700S/PR520 composite compared to the untoughened T700S/3502 composite. Temperature increases manifested primarily in resin regions adjacent to fiber tows. These results suggest that high temperature transient effects should be considered in deformation and damage models when simulating ballistic impact of composite materials.

\section{ACKNOWLEDGEMENTS}

Joel Johnston's research was supported by an appointment to the NASA Postdoctoral Program at the NASA Glenn Research Center, administered by Universities Space Research Association under contract with NASA.

\section{REFERENCES}

[1] Roberts, G. D., Pereira, J. M., Braley, M. S., Arnold, W. A., Dorer, J. D., and Watson, W. R., 2009, "Design and Testing of Braided Composite Fan Case Materials and Components," NASA TM-2009-215811.

[2] Roberts, G. D., Pereira, J. M., Revilock, D., Binienda, W. K., Xie, M., and Braley, M., 2003, "Ballistic Impact of Composite Plates and Half-Rings with Soft Projectiles," 44th AIAA/ASME/ASCE/AHS/ASC Structures, Structural Dynamics, and Materials Conference, Norfolk, VA.

[3] Roberts, G. D., Pereira, J. M., Revilock Jr, D. M., Binienda, W. K., Xie, M., and Braley, M., 2005, "Ballistic Impact of Braided Composites with a Soft Projectile," J. Aerosp. Eng., 18(1), pp. 3-7.

[4] Roberts, G. D., Goldberg, R. K., Binienda, W. K., Arnold, W. A., Littell, J. D., and Kohlman, L. W., 2009, "Characterization of Triaxial Braided Composite Material Properties for Impact Simulation,” NASA TM-2009-215660.

[5] Pereira, J. M., Roberts, G. D., Ruggeri, C. R., Gilat, A., and Matrka, T., 2010, "Experimental Techniques for Evaluating the Effects of Aging on Impact and High Strain Rate Properties of Triaxial Braided Composite Materials," NASA TM-2010-216763.

[6] Haijun, X., Lulu, L., Guangtao, C., Na, Z., Yiming, F., and Weirong, H., 2013, "Impact Response and Damage Evolution of Triaxial Braided Carbon/Epoxy Composites. Part I: Ballistic Impact Testing," Text. Res. J., 83(16), pp. 1703-1716.

[7] Pereira, J. M., Revilock, D. M., Ruggeri, C. R., Roberts, G. D., Kohlman, L. W., and Miller, S. G., 2016, "The Effects of Hygrothermal Aging on the Impact Penetration Resistance of Triaxially Braided Composites," 31st Annual American Society for Composites Technical Conference, Williamsburg, VA.

[8] Ruggeri, C. R., 2009, "High Strain Rate Data Acquisition of 2D Braided Composite Substructures," M.Sc. Thesis, The University of Akron.

[9] Ulven, C., Vaidya, U. K., and Hosur, M. V., 2003, "Effect of Projectile Shape during Ballistic Perforation of VARTM Carbon/Epoxy Composite Panels," Compos. Struct., 61(1-2), pp. 143150.

[10] López-Puente, J., Zaera, R., and Navarro, C., 2002, “The Effect of Low Temperatures on the Intermediate and High Velocity Impact Response of CFRPs," Compos. Part B Eng., 33(8), pp. 559-566. 
[11] Hosur, M. V., Vaidya, U. K., Ulven, C., and Jeelani, S., 2004, "Performance of Stitched/Unstitched Woven Carbon/Epoxy Composites under High Velocity Impact Loading," Compos. Struct., 64(3-4), pp. 455-466.

[12] Cantwell, W. J., and Morton, J., 1989, "Comparison of the Low and High Velocity Impact Response of Cfrp," Composites, 20(6), pp. 545-551.

[13] Sun, C. T., and Potti, S. V., 1996, "A Simple Model to Predict Residual Velocities of Thick Composite Laminates Subjected to High Velocity Impact," Int. J. Impact Eng., 18(3), pp. 339353.

[14] Cantwell, W. J., and Morton, J., 1991, "The Impact Resistance of Composite Materials - a Review," Composites, 22(5), pp. 347-362.

[15] Goldsmith, W., Dharan, C. K. H., and Chang, H., 1995, "Quasi-Static and Ballistic Perforation of Carbon Fiber Laminates," Int. J. Solids Struct., 32(1), pp. 89-103.

[16] Flanagan, M. P., Zikry, M. A., Wall, J. W., and El-Shiekh, A., 1999, "An Experimental Investigation of High Velocity Impact and Penetration Failure Modes in Textile Composites," J. Compos. Mater., 33(12), pp. 1080-1103.

[17] Meola, C., and Carlomagno, G. M., 2009, "Infrared Thermography of Impact-Driven Thermal Effects," Appl. Phys. A, 96(3), pp. 759-762.

[18] Meola, C., and Carlomagno, G. M., 2010, "Impact Damage in GFRP: New Insights with Infrared Thermography," Compos. Part Appl. Sci. Manuf., 41(12), pp. 1839-1847.

[19] Meola, C., Carlomagno, G. M., Ricci, F., Lopresto, V., and Caprino, G., 2011, "Investigation of Impact Damage in Composites with Infrared Thermography," 6th NDT in Progress Proceedings, Prague, pp. 175-182.

[20] Krstulovic-Opara, L., Klarin, B., Neves, P., and Domazet, Z., 2011, "Thermal Imaging and Thermoelastic Stress Analysis of Impact Damage of Composite Materials," Eng. Fail. Anal., 18(2), pp. 713-719.

[21] Meola, C., Boccardi, S., Boffa, N. D., Ricci, F., and Carlomagno, G. M., 2014, "Infrared Thermography to Evaluate Impact Damaging of Composites," 16th European Conference on Composite Materials, Seville, Spain.

[22] Meola, C., and Carlomagno, G. M., 2014, "Infrared Thermography to Evaluate Impact Damage in Glass/Epoxy with Manufacturing Defects," Int. J. Impact Eng., 67, pp. 1-11.

[23] Boccardi, S., Carlomagno, G. M., Simeoli, G., Russo, P., and Meola, C., 2016, "Evaluation of Impact-Affected Areas of Glass Fibre Thermoplastic Composites from Thermographic Images," Meas. Sci. Technol., 27(7), p. 075602.

[24] Meola, C., Boccardi, S., Boffa, N. D., Ricci, F., Simeoli, G., Russo, P., and Carlomagno, G. M., 2016, "New Perspectives on Impact Damaging of Thermoset-and Thermoplastic-Matrix Composites from Thermographic Images," Compos. Struct., 152, pp. 746-754.

[25] Meola, C., and Carlomagno, G. M., 2014, "Monitoring Materials Under Impact with Infrared Thermography," Conference Proceedings of the Society for Experimental Mechanics Series, Springer International Publishing, pp. 177-185.

[26] Papantonakis, M. R., Furstenberg, R., Nguyen, V., Moser, A., Kendziora, C. A., and McGill, R. A., 2014, "Infrared Imaging Analysis of Ballistic Impacts of Composite Armor Materials," SPIE Sensing Technology+ Applications, International Society for Optics and Photonics, p. 91050B91050B.

[27] Marcotte, F., Ouellet, S., and Farley, V., 2013, "Analysis of the Ballistic Impact Response of a Composite Material Using FAST Infrared Imagery," SPIE Defense, Security, and Sensing, International Society for Optics and Photonics, pp. 870509-870509.

[28] Vollmer, M., and Möllmann, K.-P., 2010, Infrared Thermal Imaging: Fundamentals, Research and Applications, John Wiley \& Sons.

[29] Widger, W. K., and Woodall, M. P., 1976, "Integration of the Planck Blackbody Radiation Function," Bull. Am. Meteorol. Soc., 57(10), pp. 1217-1219.

[30] ASTM D8101/D8101M-17, 2017, Standard Test Method for Measuring the Penetration Resistance of Composite Materials to Impact by a Blunt Projectile, ASTM International, West Conshohocken, PA.

[31] ASTM E1862, 2014, Standard Practice for Measuring and Compensating for Reflected Temperature Using Infrared Imaging Radiometers, ASTM International, West Conshohocken, PA.

[32] ASTM E1933-14, 2014, Standard Practice for Measuring and Compensating for Emissivity Using Infrared Imaging Radiometers, ASTM International, West Conshohocken, PA. 